Mundo Agrario vol. 18, no 38, e062, agosto 2017. ISSN 1515-5994

Universidad Nacional de La Plata.

Facultad de Humanidades y Ciencias de la Educación.

Centro de Historia Argentina y Americana

\title{
Conflitos e Desafios de populações tradicionais na Amazônia brasileira: o caso da Reserva Extrativista do Extremo Norte do Estado do Tocantins
}

\author{
Conflict and Challenges of traditional populations of the Brazilian \\ Amazon: the case of Extractive Reserve in the Far North of Tocantins \\ State
}

\section{Dayane Rouse Neves Sousa *, Marcelo Leles Romarco de Oliveira **}

* Universidade Federal de Viçosa, Brasil, ** Departamento de Economia Rural da Universidade Federal de Viçosa, Brasil | sousadayane@ymail.com; mlromarco@yahoo.com.br

\section{PALAVRAS CHAVE RESUMO}

Babaçu Este artigo analisa os conflitos ocasionados em virtude do processo de criação da Resex do Extremo Norte até o ano de 2015. A metodologia escolhida foi o estudo de caso, com informações coletadas por meio de documentos escritos

Conflito e entrevistas. Os resultados indicam que, passados 24 anos de existência da Resex do Extremo Norte, as famílias ainda não moravam dentro da área desta Unidade de Conservação, mas em comunidades do entorno, o que tem

População tradicional contribuído para a intensificação na disputa pelos recursos contidos em tal território e nos conflitos entre população

Reserva extrativista tradicional e fazendeiros.

Amazônia brasileira

Estado do Tocantins

\section{KEYWORDS}

Babassu

Conflict

Traditional population

Extractive reserve

Brazilian Amazonia

State of Tocantins

\section{ABSTRACT}

This article analyzes the conflicts caused by virtue of the creation process Resex in the Far North until the year 2015. The chosen methodology was the case study, with information collected from written documents and interviews. The results indicate that after 24 years of existence of Resex the families still did not live within the area of this Conservation Unit, but in surrounding communities, which has contributed to the intensification in dispute for resources and conflicts between traditional population and farmers. 


\section{Introdução}

A questão agrária brasileira sempre esteve relacionada com o modo de apropriação e desapropriação da terra e sua consequência foi, e ainda é, o surgimento do conflito por terra. Martins (1990) argumenta que a essência desse tipo de conflito tem sua raiz na própria reprodução do capitalismo, no Brasil isso ocorre desde sua colonização. Fruto disso, a relação capitalista era e é caracterizada pela reprodução de suas contradições, quais sejam: concentrações de terra, renda e poder; desigualdade social e expropriação violenta. Essa realidade brasileira, também, é encontrada em outros países latino-americanos como Argentina, Colômbia, Uruguai e Venezuela.

Nesse contexto, autores como Santos (2002) apontam que um dos elementos marcantes nesses países é a "violência estrutural”, fomentada principalmente pela concentração da propriedade da terra, corrupção, efeitos das políticas de ajuste estrutural, desigualdade social, concentração de renda, exploração e precarização nas relações de trabalho no campo.

As similaridades dos apontamentos realizados por Martins (1990) e Santos (2002) deixam claro que o meio rural dos países da América Latina está carregado de problemas de ordem econômica, social, trabalhista, política e ambiental. Em especial no Brasil, por ser um país com extensa área territorial e por possuir a maior floresta tropical do mundo - a Floresta Amazônica -, os conflitos por terra e ambientais são mais acentuados. Ainda em 2017, na maior parte do território da Amazônia Brasileira existiam conflitos que provavelmente demorarão a ser solucionados, mesmo que o Estado brasileiro esteja criando "espaços territoriais especialmente protegidos pelo poder público” (Brasil, 1989).

Criados com a finalidade de mitigar os conflitos agrários no Brasil destaca-se as Reservas Extrativistas - Resex’s - uma modalidade específica de Unidade de Conservação (UC). Cedendo a mobilização dos movimentos seringueiros da Amazônia, o então presidente da república José Sarney, por meio do Decreto no 98.897 de 30 de janeiro de 1990 cria as primeiras Resex brasileiras, dentro do escopo das políticas públicas ambientais, sendo caracterizadas como espaços territoriais especialmente protegidos pelo poder público com uso concedido às populações tradicionais por meio do Contrato de Concessão de Direito Real do Uso (CCDRU), que permite o uso sustentável dos recursos naturais por esses atores. Assim, o Estado passaria a reconhecer e garantir o direito dessas populações em permanecerem em seus territórios. Cabe esclarecer que as reservas extrativistas estão no grupo das Unidades de Conservação de Uso Sustentável, que são modalidades de espaços protegidos que permitem que as populações tradicionais vivam e explorem os recursos de forma sustentável.

Para entender o processo de criação de uma Resex escolheu-se a Reserva Extrativista do Extremo Norte do Estado do Tocantins por sua localização típica - Amazônia Brasileira - e os conflitos nela existentes. Portanto, o presente artigo analisa os conflitos ocasionados em virtude do processo de sua criação até 2015.

\section{Métodos}

A Resex do Extremo Norte foi criada em 20 de maio de 1992, possuindo 9.280 hectares, localizada nos municípios de Buriti do Tocantins, Carrasco Bonito e Sampaio, no Estado do Tocantins. Estes municípios compõem a região conhecida como Bico do Papagaio e o território da Amazônia Brasileira. A Figura 1 ilustra a localização da Resex no território brasileiro e na região do Bico do Papagaio 


\section{Figura 1}

\section{Localização da Reserva Extrativista do Extremo Norte do Estado do Tocantins e na região do Bico do Papagaio}

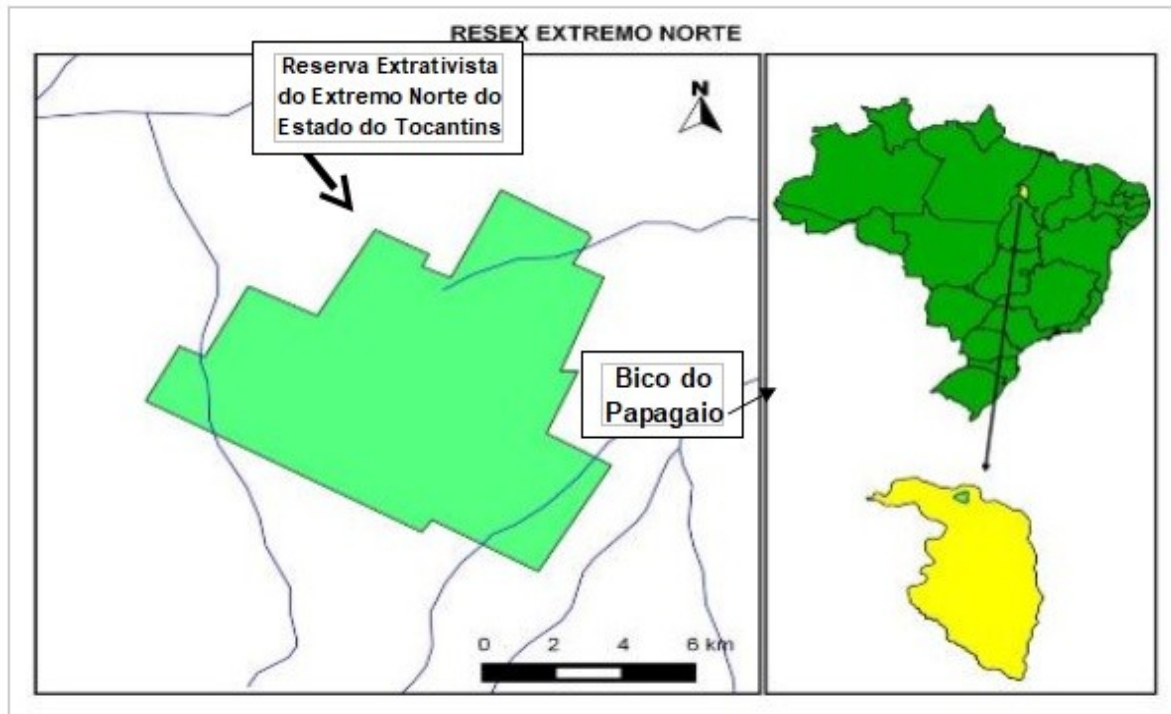

Fonte: UFV/ICMBio 2014

No ano de 2014 foram identificadas 237 famílias, com uma população de 893 pessoas (UFV/ICMBio, 2014). Foi aplicado um conjunto de técnicas para a coleta dos dados que se dividiu em três fases. A primeira fase foi dedicada à pesquisa bibliográfica e ao levantamento de dados secundários que estão à disposição para pesquisas, como decretos, planos e projetos relacionados à área da pesquisa.

Já na segunda fase foi realizado o trabalho de campo, que consistiu em dois momentos. O primeiro foi o précampo, que aconteceu durante o $2^{\circ}$ Seminário para Apresentações dos Resultados Preliminares do Cadastramento e Diagnóstico Socioprodutivo em Unidades de Conservação, realizado em Brasília, em agosto de 2014. Na ocasião, foi possível entrevistar três pessoas ligadas a esta unidade de conservação. Por meio das informações coletadas foi possível realizar o planejamento do trabalho de campo nesta unidade de conservação.

Posteriormente a este planejamento foi realizado o trabalho de campo entre os dias 27 de outubro e 2 de novembro de 2014, com a realização de 14 entrevistas semiestruturadas junto às famílias da Resex do Extremo Norte. Ao longo do texto, as declarações dos entrevistados serão representadas por letras do alfabeto. Esta escolha teve por objetivo resguardar a identidade dos informantes. Além desse instrumento de coleta de dados, os depoimentos realizados com outras famílias desta UC também serviram de suporte para o entendimento da realidade estudada.

A seleção dos informantes entrevistados seguiu o critério de intencionalidade, ou seja, a escolha dos participantes levou em consideração aquelas pessoas que vivenciaram o antes e o depois da criação da Resex do Extremo Norte. Este critério permitiu observar de forma mais apurada a percepção destes atores sobre as transformações provocadas pela criação desta reserva.

Com esse critério definido, uma das formas encontradas para se chegar aos entrevistados foi por meio da indicação de alguns moradores previamente mapeados. Ao chegar a cada comunidade, contatava-se a liderança do local para que esta pudesse apontar quais eram as pessoas que poderiam contribuir com a pesquisa. Depois de realizada a primeira entrevista em cada comunidade, utilizou-se o método da bola de neve, no qual um entrevistado indicava outro de acordo com a demanda da pesquisa. Por fim, a última fase consistiu na análise dos dados do questionário do Banco de Dados da UFV/ICMBio referente a esta unidade de conservação em estudo. Cabe destacar que a pesquisadora também participou da coleta desses dados. 


\section{Resultados e discussão}

\subsection{Do conflito pela terra à criação da Reserva Extrativista do Extremo Norte}

No território da Amazônia brasileira a intensificação da ocupação desta região vai ocorrer, segundo Pereira (2010), principalmente entre as décadas de 1970 e 1980, quando empresas privadas e proprietários do centro-sul do país passaram a adquirir títulos e terras do Estado e instalaram seus empreendimentos agropecuários. Todavia, para a ocorrência desse fato houve muitas expropriações e expulsões violentas de indígenas e trabalhadores rurais de suas terras. No caso dos trabalhadores rurais a maioria era migrante que ocuparam terras devolutas e que, há muitos anos, viviam em suas posses sem ter algum documento que os caracterizara como proprietários.

Outro motivo de intensificação da ocupação na região se refere à promoção de políticas integracionistas, econômicas e desenvolvimentistas do Governo Militar, que fomentou a integração da Região Norte com o CentroSul do país. Para que isso acontecesse, um conjunto de obras de infraestrutura, como as rodovias Transamazônica e a Belém-Brasília, foi construído para integrar o país. Essas ações motivaram, ainda mais, os empresários rurais a investirem em busca de terra e do lucro fácil na Amazônia. Em razão disso, estes conseguiram a posse dos títulos de terra e os trabalhadores rurais passaram a ser vistos como ilegais pelos representantes dos órgãos do Estado. Além disso, os trabalhadores rurais foram acusados de impedir a execução dos projetos agropecuários âncora do “desenvolvimento" e do "progresso" da região e do Brasil (Pereira, 2010, p. 1).

Para Martins (1991), houve um movimento capitalista de ocupação do território da Amazônia representado pela grande fazenda, banco, casa de comércio, rodovia, juiz, cartório, Estado, que passou a expulsar e expropriar violentamente os trabalhadores rurais e suas famílias que moravam nas terras devolutas e viviam de uma economia de abastecimento do autoconsumo familiar e que não tinham documento que comprovasse a sua posse da terra, conhecido como posseiro (descrito neste trabalho como trabalhador rural). Como forma de continuarem nas terras em que moravam há vários anos, os trabalhadores rurais tentavam resistir às ações violentas dos proprietários e empresários rurais. É a partir do momento no qual os proprietários juntamente com seus pistoleiros expulsaram as famílias dos trabalhadores rurais de suas terras e os mesmos resistiram a este ato é que se iniciam os conflitos e a violência no campo.

Na busca pela posse da terra nesta região, grileiros incendiaram povoados; fazendeiros lutaram pelas terras com os trabalhadores rurais; representantes de órgãos públicos, jagunços, pistoleiros, fazendeiros, grupos econômicos lutaram contra os trabalhadores rurais. É no contexto de agressões, tiroteios e mortes que se deu a rotina daqueles que viveram na região do Bico do Papagaio entre as décadas de 1950 a 1990 (Martins, 1991). No prefácio do livro O massacre dos posseiros, publicado em 1981, Martins enfatiza a aguda violência que ocorreu contra os homens do campo da região do Bico do Papagaio, na qual o respeito à vida e à pessoa, o direito de trabalho e de sobrevivência são aspectos que estavam longe de se concretizar no cotidiano dos trabalhadores rurais. Martins ainda revela que:

Os que cometem tais violências são justamente ilustres figuras da República, através de uma cadeia de interesses e de relações que vai do senador, do deputado, do ministro, até do oficial, ao juiz, ao delegado de polícia, ao policial, ao soldado, ao oficial de justiça, ao jagunço, ao pistoleiro profissional. Um retrato espantoso de banditismo acobertado por um infernal aparato de poder e pela certeza da impunidade (Martins, 1981, p. 9).

É por meio dessas “ilustres figuras da República”, conforme chamou Martins, e da ação do juiz-grileiro em servir o policial ou o soldado como força de cobertura para as violências no campo, que jagunços e pistoleiros agrediram e/ou mataram membros de famílias desta região (não respeitando crianças, grávidas, idosos e mulheres), queimaram casas e destruíram roças, expulsando famílias de suas terras, as quais lá viviam há mais de 40 anos, em alguns casos. E, assim, o número de mortes em razão dos conflitos pela posse da terra foi aumentando. Também é importante destacar a participação dos representantes da Igreja Católica, principalmente, Padre Josimo e o missionário italiano Nicola Arpone, e da Comissão Pastoral da Terra (CPT) na busca de minimizar e até mesmo solucionar os conflitos pela a terra na região do Bico do Papagaio. 
De acordo com Behr (1995), entre as décadas de 1980 a 1990, a região do Bico do Papagaio era caracterizada pela prevalência dos latifundiários que tinham o direito de propriedade sobre os recursos naturais, principalmente, sobre os babaçuais e a pecuária extensiva. Isto é, as áreas dos babaçuais eram exploradas em benefício do proprietário da terra. Assim, os migrantes nordestinos, ou seja, os trabalhadores rurais eram impedidos de quebrar e coletar os cocos de babaçu nas propriedades privadas. Segundo o autor, ainda, estes grupos viviam em povoados paupérrimos, construídos no único espaço físico que lhes sobrou naquela imensa região, a pequena faixa situada entre as cercas das grandes fazendas e as estradas. As casas eram de parede de barro e cobertas com folhas de palmeira e no seu interior não tinham quase nada. A coleta do babaçu e a agricultura para o consumo da família eram as principais atividades econômicas desenvolvidas. Além disso, uma das formas de obtenção de renda na região era a venda da força de trabalho familiar ao fazendeiro, que acontecia raramente.

Diante disso, a partir do final da década de 1980, houve um processo de reivindicação pela Reforma Agrária por parte dos representantes dos Sindicatos dos Trabalhadores Rurais e dos movimentos sociais ligados à Igreja Católica. Além da reivindicação pelo direito à posse da terra, enquanto meio de sobrevivência para as famílias, esses atores lutavam para acabar com os conflitos pela terra na região.

Assim sendo, as mulheres quebradeiras de coco babaçu assumiram a luta pelo acesso à terra e pelo uso sustentável do babaçu. Nesse movimento de luta destaca-se o papel da líder dona Raimunda Quebradeira de Coco, que, através da sua persistência no movimento, obteve como resultado inicial, em 1986, a desapropriação de uma área na região do município de São Miguel, no atual Estado do Tocantins, para a criação do Assentamento Sete Barracas. Como não foram todas as famílias que conseguiram ser beneficiadas deste projeto, dona Raimunda continuou na luta para que mais famílias fossem contempladas por meio do acesso à terra.

Nos anos subsequentes, no início da década de 1990, emergiram, na Amazônia Brasileira, intensas mobilizações dos movimentos seringueiros para a criação de reservas extrativistas. Desta forma, dona Raimunda também liderou a luta na região do Bico do Papagaio para que fosse criado esse tipo de território que permitiria garantir o uso desse espaço pelas famílias extrativistas, sobretudo, as das quebradeiras de coco babaçu. Naquele momento essa preocupação era justificada em razão da recente criação do Estado do Tocantins, em 1988, que acirrava ainda mais os conflitos já existentes na região entre fazendeiros e população tradicional que explorava o babaçu. Entre os relatos coletados durante a pesquisa, um dos entrevistados sintetizou como era esse cenário conflituoso entre fazendeiros e quebradeiras de coco babaçu.

Os capetagens [se referindo a pessoas ruins], que eram os fazendeiros, jagunços ou pistoleiros, chegavam aos locais onde elas estavam coletando o coco e quebrando o coco e diziam que iam jogar calagem em cima e que tinham que sair da terra dele, que na terra dele não era espaço de quebradeira coco tá lá quebrando cerca. Diziam que não iam quebrar cerca e iam quebrar coco e quebrar cerca. Diziam também que iam colocar fogo nos pastos, porque elas usavam muito a casca do coco para a fabricação de carvão. Além disso, também há os relatos, [...], de que o fazendeiro chegou e estava um grupo de quebradeiras de coco fazendo o trabalho delas e ele disse que, da próxima vez que ele encontrasse quebradeiras de coco nas terras dele, em cada uma destas quebradeiras ele ia deixar um menino. [...] isso é real, aconteceu de verdade, as pessoas contam isso (Relato do Entrevistado O, 2014).

A partir de tal relato, pode-se notar o tipo das ameaças que as quebradeiras de coco vivenciaram para coletar e quebrar coco babaçu, além de terem experienciado o conflito entre fazendeiros para o uso deste recurso natural. Isso retrata uma das formas de violência contra a mulher extrativista realizada pelos "donos" da terra e seus pistoleiros

Diante desta situação dona Raimunda e outras lideranças das quebradeiras de coco se mobilizaram objetivando a criação de uma reserva extrativista próxima à área do Assentamento Sete Barracas. O grupo obteve sucesso e foram criadas três reservas extrativistas: Mata Grande (no Estado do Maranhão), Ciriaco (no Estado do Maranhão), e Extremo Norte do Estado do Tocantins (no Estado do Tocantins), ambas no ano de 1992. 
A criação dessas três reservas extrativistas gerou impacto político não só para a região, mas para todo o país, uma vez que essas unidades de conservação foram criadas 14 dias antes do início da II Conferência das Nações Unidas sobre Meio Ambiente e Desenvolvimento, evento conhecido mundialmente como Eco-92 ou Rio-92, realizado na cidade do Rio de Janeiro-RJ, entre os dias 3 a 14 de junho do mesmo ano.

A criação dessas unidades de conservação dava ao país uma conotação de preocupação em conservar o meio ambiente e em dar visibilidade às populações tradicionais que viviam ou exploravam recursos naturais nesses territórios. Buscou-se mostrar, assim, que o Brasil estava seguindo as diretrizes apontadas pelo Relatório de Brundtland, conhecido também como Relatório Nosso Futuro Comum, elaborado em 1987, que definia o conceito de desenvolvimento sustentável como fio norteador das próximas discussões sobre meio ambiente e homem. Ademais, o governo brasileiro queria demonstrar, neste evento, o progresso em direção à redução do desmatamento da Amazônia através da criação das reservas extrativistas.

\subsection{Da criação da Reserva Extrativista do Extremo Norte à resistência para sua regularização}

Refletir sobre a criação da Resex do Extremo Norte nos faz apontar alguns elementos que ajuda a entender porque ainda hoje não ocorreu a regularização fundiária desta reserva. Apesar da criação desta unidade de conservação ter sido uma conquista orquestrada pelo movimento das quebradeiras de coco encabeçado por dona Raimunda, as famílias que seriam beneficiárias por muitos anos não tiveram a dimensão dessa conquista, principalmente, por acreditarem que essa conquista do território não atenderia os seus anseios. Essa justificativa estaria associada à intensificação dos conflitos entre extrativistas e fazendeiros que a Reserva trouxe, bem como à restrição do uso do babaçu. Por outro lado, as famílias não tinham qualquer entendimento do que seria uma reserva extrativista e, para muitos, a Resex do Extremo Norte era uma forma de assentamento rural da reforma agrária, ou seja, uma forma de ter acesso à terra. Assim, tendo por base a percepção do entrevistado O (2014), se esqueceram de dizer às famílias das quebradeiras de coco que esse espaço era uma reserva extrativista, bem como os seus direitos e deveres sobre este território.

Yohannes (2013) também acredita que o processo de criação da Resex do Extremo Norte não teria, de fato, envolvido as comunidades e que esse procedimento teria sido rápido e apressado, talvez em função do Estado dar uma resposta aos representantes dos países presentes na Eco-1992, no qual o Brasil estaria fazendo a sua parte em relação à conservação do meio ambiente. Além disso, diante de várias nações, o país estaria apresentando a sua política ambiental, que preconizava, entre outras questões, a conservação das florestas. Para Dias (2005), a criação e anunciação das cinco resevas extrativistas durante a Eco-92 não passou de um marketing ecológico do presidente da República.

Do ponto de vista prático, a criação da Resex do Extremo Norte provocaria alterações no cotidiano de todos envolvidos principalmente no que se refere ao direito de acesso à terra e uso dos recursos por parte das comunidades beneficiadas. Além disso, a criação da Resex provocaria a desapropriação de terras de pecuaristas da região e que se rebelaram contra a criação. Essa ação de desapropriação estaria constituída através Decreto $n^{0} 535$, em seu art. $2^{\circ}$ que trazia a seguinte redação:

O Poder Público deverá proceder às desapropriações que se fizerem necessárias e, nos termos do art. $4^{\circ}$ do Decreto ${ }^{\circ}$ 98.897, de 30 de janeiro de 1990, a outorga dos contratos de concessão de direito real de uso (CCDRU) à população com tradição extrativista. Parágrafo único. Caberá, ainda, ao Poder Executivo, a permanente gestão no sentido de assegurar a eficaz destinação da área descrita no art. $1^{\circ}$ deste decreto (Brasil, 1992).

Diante desta lei, o representante do Estado, na ocasião o Instituto Brasileiro do Meio Ambiente e Recursos Naturais Renováveis (IBAMA), deveria desapropriar as terras dos fazendeiros para que as famílias das quebradeiras de coco pudessem usufruir do território e dos recursos naturais da Resex por meio do CCDRU. Cabe 
destacar que a partir de agosto de 2007, o Estado criou o Instituto Chico Mendes de Conservação da Biodiversidade (ICMBio) para assumir a gestão de todas as unidades de conservação no Brasil, incluindo nesse bojo as resex's.

Sendo assim, a partir do momento que ocorreu a criação de tal território, os fazendeiros tomaram conhecimento do fato e, com medo de perderem suas terras ou de receberem uma indenização “injusta” entraram em contato com os políticos para que impedissem a desapropriação da terra e a regularização da Reserva.

Essa mobilização por parte dos fazendeiros, que, inclusive, tinham influência política em Brasília contribuiu para a inércia do Estado e, por anos, a Resex, na verdade, “ficou só no papel”. Conforme se observa no relato de um dos entrevistados, os políticos têm uma relação de influência forte com os fazendeiros desta região:

Outra coisa, o apoio político a gente não tem. Nem em nível estadual e nem em nível municipal. Todos os prefeitos que entram são contra a Reserva. Porque são os fazendeiros que patrocinam as campanhas deles. Então, se eles [prefeitos] ficarem a favor da Reserva, no outro ano os fazendeiros não apoiam eles [prefeitos]. Aí todos [prefeitos] que entram, na hora de pegar o apoio nosso, eles falam que apoiam a Reserva na nossa frente, mas na hora que ganha, nem senta com a gente para conversar sobre a Reserva (Relato do Entrevistado A, 2014).

Sobre a inércia do Estado e a falta de mobilização por parte das comunidades, cabe destacar que os fazendeiros, se aproveitando desse contexto, fizeram uma intensa propaganda negativa sobre o que era a Reserva Extrativista, utilizando, inclusive, de artifícios de pressão junto às comunidades, como, por exemplo, proibindo as mulheres de irem quebrar coco nos babaçuais e impossibilitando os homens de colocar roçados nas suas terras. Essa pressão estava voltada, principalmente, para aquelas 60 famílias que residiam nos dois povoados (Vilinha e Centro do Gonçalo) localizados no interior da Resex.

Seguindo essa observação, Yohannes (2013) revela que a oposição representada pelos fazendeiros, políticos locais e outras elites, irritados com a possibilidade de perder suas terras, faziam campanha contra a Resex. Esta autora ainda afirma que os funcionários da Prefeitura de Carrasco Bonito, juntamente com os fazendeiros, espalharam mentiras sobre a finalidade desta unidade de conservação e o impacto que a mesma teria na comunidade. Além disso, disseram que a Resex do Extremo Norte seria uma reserva puramente ecológica e que ninguém conseguiria acessar e usar seus recursos para extração. Assim, esses atores sociais acreditavam que as famílias das quebradeiras de coco perderiam o interesse na existência desta Resex.

Diante disso, os representantes dos Sindicatos dos Trabalhadores Rurais do Bico do Papagaio junto com as lideranças dos extrativistas começaram a buscar informações que possibilitassem entender, de fato, quais seriam os benefícios que a Resex traria para eles. Essas mobilizações, iniciadas pelas lideranças e suas famílias, começaram a surtir efeitos e incomodar os fazendeiros da região, pois as ameaças de morte passaram a acontecer com frequência. Além disso, aqueles que estariam envolvidos nessas mobilizações e discussões passaram a ser punidos pelos fazendeiros da região, uma vez que muitos não conseguiam mais trabalho como diaristas nas fazendas e, ainda, perderam a possibilidade de arrendar terras para fazer os seus plantios.

No outro campo de resistência à consolidação da Resex, os grupos contrários (fazendeiros e políticos) moveram vários atos e ações propondo ao Ministério Público Federal (MPF) a extinção do decreto de criação da Resex do Extremo Norte. Castilho (2009) pontua os seguintes argumentos contidos nessa primeira ação, em 1993: 1) Utilização inadequada do solo dado o vasto desmatamento da área de babaçu; 2) conflitos com os fazendeiros em razão da existência desta unidade de conservação; 3) falta de organização e mobilização entre os extrativistas de babaçu para justificar a sua existência.

Já a segunda ação ocorreu no mesmo ano, quando a equipe do IBAMA/CNPT (Centro Nacional de Desenvolvimento Sustentado das Populações Tradicionais) e do INCRA (Instituto Nacional de Colonização e Reforma Agrária) foi impedida pelos fazendeiros de realizar o trabalho de avaliação das benfeitorias das propriedades para que o processo de regularização fundiária ocorresse (Castilho, 2009). Foi neste mesmo ano 
(1993), um pouco antes desta ação, que os fazendeiros destruíram os dois povoados que existiam na área da Resex do Extremo Norte, ou seja, nenhuma família tradicional permaneceu neste território.

Em julho de 1994, o IBAMA criou uma equipe composta por representantes do IBAMA, INCRA, Sindicatos dos Trabalhadores Rurais e moradores da região do Extremo Norte do Tocantins e Maranhão para analisar as atuais situações das reservas extrativistas do Extremo Norte, Ciriaco e Mata Grande. Assim, nesse mesmo ano, esta equipe visitou as comunidades do entorno da Resex do Extremo Norte (Vinte Mil, Sampaio e Carrasco Bonito) e concluiu que as atuais condições ambientais e sociais já não justificavam a consolidação desta unidade de conservação, pois a floresta de babaçu tinha sido destruída e a população tradicional já não praticava atividades extrativistas de babaçu (Castilho, 2009).

Neste mesmo ano, o decreto de criação da Resex expirou. Isto ocorreu em razão do Estado não ter regularizada a questão fundiária deste território, uma vez que as ações de desapropriação devem ser realizadas pelo Estado no prazo máximo de dois anos após a instituição da lei para fins de interesse social (Dias, 2005).

Diante do resultado da pesquisa realizada pela equipe do IBAMA, no ano de 1994, nessas três reservas extrativistas, o Ministério do Meio Ambiente (MMA), em 1996, apoiou as conclusões da pesquisa realizada pelo o IBAMA, INCRA, Sindicatos dos Trabalhadores Rurais e moradores da região do Extremo Norte do Tocantins e Maranhão, e fez uma recomendação formal ao presidente da república por meio do projeto de lei $n^{0} 2.598$ para realizar a extinção das reservas extrativistas do Extremo Norte e da Mata Grande (Castilho, 2009).

Enquanto isso, a população de ambas as reservas extrativistas e as organizações regionais que as representavam não tinham conhecimento da legislação (Lei $n^{0}$ 2.598) proposta para a sua extinção. Somente em 1999, os movimentos sociais da região do Bico do Papagaio e do Maranhão descobririam este processo de extinção do decreto dessas resex's e enviariam uma série de cartas, ofícios e moções ao MMA, CNPT e MPF solicitando o cancelamento do processo (Castilho, 2009). Neste mesmo ano, o Sindicato dos Trabalhadores e das Trabalhadoras Rurais de Carrasco Bonito (STTR-CB) foi criado para dar encaminhamento aos assuntos da Resex do Extremo Norte juntamente com estas organizações. Até então não havia ocorrido, de fato, a extinção do decreto de criação desta unidade de conservação.

No que se refere à falta de mobilização por parte das famílias, percebeu-se que isso também foi outro elemento que contribuiu para que a Reserva não fosse regularizada e não saísse do papel, pois as quebradeiras só tiveram ciência do que era uma reserva extrativista depois de quase dez anos após o decreto de criação da mesma. Neste contexto, em 2001, foi criada a Associação da Reserva Extrativista do Extremo Norte, denominada ARENT, para representar os extrativistas desta unidade de conservação, o que só foi possível em razão da atuação de mediadores como: Movimento Interestadual das Quebradeiras de Coco (MIQCB), STTR-CB, CPT e Conselho Nacional das Populações Extrativistas (CNS). Até então, as famílias tinham resistência em aceitar a Resex, conforme se observa no relato.

Nós tínhamos resistência [à Resex]. A maioria dos trabalhadores não tinha consciência de como essa reserva funcionava, eles acreditavam no que a prefeitura dizia que era uma reserva legal, uma reserva que era proibida a entrada da gente. Não era tão divulgado o que era a reserva. Aí isso deixava os trabalhadores rurais, o quebrador de coco e os proprietários [desconfiados]. Então todo esse povo, o que era proprietário já não queria abrir mão da sua área, e os trabalhadores rurais com medo do fazendeiro não deixar ele fazer a sua roça, as quebradeiras de coco ficavam imaginando e preocupadas, onde elas iam quebrar o coco se tivesse um policial com uma arma na mão, empatando quando essas pessoas iam entrar dentro. Então essas coisas deixaram todo mundo e a comunidade confusa (Relato do Entrevistado J, 2014).

Como forma de atender às reivindicações realizadas em 1999, e pelos movimentos sociais da região do Bico do Papagaio e do Maranhão em 2001 o MMA solicitou vistoria in loco nas resex’s do Extremo Norte e Mata Grande que originou um laudo técnico-científico, realizado pelo CNPT/IBAMA (CNPT, 2001, p. 15 apud Castilho, 2009, 
p. 44).

Diante deste resultado o MMA, em agosto de 2002, criou uma comissão interinstitucional para fazer o cadastro dos beneficiários da Resex e o levantamento socioeconômico dessas famílias para, posteriormente, proceder aos trabalhos para a regularização fundiária. Assim, nesse mesmo ano, foi realizado por meio do Instituto de Terras do Tocantins (ITERTINS) um estudo para auxiliar o processo de desapropriação das propriedades rurais localizadas no seu perímetro (Castilho, 2009).

Como o trabalho da ITERTINS também serviria para dar subsídios às medidas compensatórias do Projeto de Aproveitamento Hidroagrícola Sampaio, de acordo com o jurídico do IBAMA, o laudo apresentou erros e falhas, apresentando este parecer como parâmetro do laudo de vistoria do Projeto Hidroagrícola e não da Resex do Extremo Norte. O parecer jurídico do IBAMA rejeitou as informações do Laudo da Vistoria e Avaliação da Resex (Castilho, 2009). Ou seja, pela segunda vez o Estado tentava realizar o trabalho de regularização fundiária do território desta unidade de conservação e as ações deste trabalho não tiveram sucessos.

Em 2006, houve a terceira tentativa de realizar o levantamento das propriedades localizadas no interior do território da Resex por meio de uma consultoria contrata pelo IBAMA/CNPT. Este levantamento foi realizado nos cartórios municipais da região com auxílio de representantes do STTR-CB, os quais identificaram 58 proprietários, sendo que apenas 12 nomes constatavam no laudo apresentado pelo ITERTINS (Castilho, 2009). Percebeu-se assim que não há dados seguros sobre o número real de propriedades. Pela terceira vez, as ações de regularização fundiária não se concretizaram.

Neste contexto, foi possível verificar, ainda, que a atividade de gestão da Resex do Extremo Norte só ocorreu a partir de 2007, quando se criou o ICMBio, que possui um funcionário responsável para fazer um trabalho efetivo na Resex do Extremo Norte. Até então, havia apenas uma pessoa que tinha uma função gratificada para ser responsável pelas ações da Reserva. Além disso, o IBAMA de Palmas, no Estado do Tocantins, recebia recursos financeiros para fazer fiscalização nesta UC, porém esta atividade ocorria com pouca frequência. Apesar disso, a demarcação dos limites da Resex ocorreu, em 2012, com vinte sinalizações colocadas no seu perímetro e uma das indicações que mais surtiu efeito, tanto para os fazendeiros quanto para os extrativistas, foi a placa na qual estava escrito: Reserva Extrativista Extremo Norte do Tocantins. Segundo Yohannes (2013), as sinalizações dentro desta unidade de conservação representaram, pela primeira vez, a presença física da existência da Reserva Extrativista.

Apesar destas ações realizadas pelo representante do Estado para dar início ao processo de regularização fundiária, até em maio de 2017, isso ainda não tinha sido resolvido. Além disso, o decreto de criação desta unidade de conservação não havia sido extinto. Isto significa que, há mais de 24 anos, os extrativistas estão esperando a desapropriação da terra para usufruir, sem "ter briga [conflitos entre extrativistas e fazendeiros]" do território da Resex do Extremo Norte (Relato da Entrevistada H, 2014).

Portanto, diante desta discussão, questiona-se o que melhorou e o que piorou após a existência de tal Reserva na vida desta população tradicional (famílias das quebradeiras de coco). Na percepção dos entrevistados, de uma forma geral, a melhoria está relacionada no sentido das famílias terem acessado as políticas públicas destinadas aos extrativistas da Reserva, como: o Programa Bolsa Verde e o Programa de Habitação das Casas das Quebradeiras de Coco. O relato que segue mostra esta percepção: "Melhorou para muita gente, porque tem muita gente que recebe benefícios” (Relato da Entrevistada N, 2014).

Ademais, os extrativistas passaram a se organizar coletivamente por meio da ARENT, que vem trazendo benefícios às famílias, como a implantação da Usina de Beneficiamento de Coco Babaçu dos Comunitários da Resex Extremo Norte do Estado do Tocantins, que foi uma estratégia para agregar valor e comercializar a produção do babaçu, além de gerar renda a essa população da Resex.

Ainda, de acordo com o relato do Entrevistado A (2014), a criação da Reserva trouxe benefício ao município de Carrasco Bonito, pois, todos os meses a Prefeitura Municipal recebe o ICMS Ecológico no valor de, aproximadamente, $\mathrm{R} \$ 55.000,00$ por mês referente a existência da Resex. No entanto, em relação ao que piorou, 
os entrevistados indicaram a intensificação dos conflitos ocasionados pela disputa do território da Resex entre fazendeiros e extrativistas. Consequentemente, isso trouxe como implicações as restrições ao uso dos babaçuais, a redução da quantidade de frutos extraídos e as tensões entre extrativistas e fazendeiros, ou seja, o fato de adiar a regularização fundiária potencializou a existência dos conflitos ambientais entre tais atores.

\section{Considerações Finais}

A partir das discussões realizadas, acredita-se que a população tradicional que tem relação com esta resex em estudo deveria ter o direito de uso deste território e dos seus recursos naturais. Entretanto, a Resex do Extremo Norte tem 24 anos de existência e, até então, o Estado não havia regularizado a questão fundiária, o que resultou no fato de que as famílias das quebradeiras de coco não têm a garantia de extração do babaçu e, tampouco, o acesso a terra deste território.

Percebe-se, então, que a não efetividade da atuação do Estado permitiu que as demandas existentes das populações tradicionais não fossem atendidas. A falta de proximidade, de regulamentação e de controle da Resex criou algo que existe formalmente, mas distante da realidade, segundo confirmou-se nos relatos desta pesquisa. Se, por um lado, após a criação da Reserva foram construídas casas de alvenaria e distribuídas entre algumas famílias que ali moravam, também foi implantada a Usina de Beneficiamento de Coco Babaçu dos Comunitários da Resex Extremo Norte do Estado do Tocantins e algumas famílias passaram a receber recursos financeiros do Programa Bolsa Verde.

Por outro lado, intensificaram-se os conflitos entre fazendeiros e a população tradicional ali existente, levando à restrição, por parte dos fazendeiros, da extração do babaçu. Alguns fazendeiros ainda permitem a coleta do coco, entretanto, as dificuldades com o transporte fazem com que a quantidade extraída diminua bastante. A quebra nos babaçuais é totalmente proibida e as famílias têm de transportar os cocos inteiros, o que gera grandes volumes e custos com baixo retorno financeiro. É importante enaltecer que a extração do babaçu é bastante relevante na vida desta população, uma vez que dele se obtém alimento, renda e, ainda, sua utilização na construção das casas ali existentes. Vale ressaltar ainda que, mesmo com as dificuldades impostas pelos fazendeiros, as famílias continuam fazendo a extração do babaçu, porém em menor quantidade.

Desta maneira, o que se percebe é que esses anos de indefinição da efetivação da Resex do Extremo Norte têm trazido consigo diversos problemas, uma vez que a falta de regulamentação e fiscalização suficiente permite o aumento do desmatamento dos babaçuais para a expansão da pecuária. Além disso, deixa uma importante fonte de renda nas mãos dos fazendeiros em detrimento das famílias.

A fiscalização de cerca de 9.280 hectares é realizada por um único funcionário do ICMBio e isso acontece desde de 2007, pois antes não existia sequer servidor responsável pelos trabalhos nesta unidade de conservação. Já a regulamentação ineficaz se dá através da inexistência de regimento específico que delimite data, local e forma para o uso deste território. Outro fator relevante é a falta de conhecimento dos direitos adquiridos por parte da população tradicional, o que facilita a postergação da solução por parte dos fazendeiros interessados. Além disso, o apadrinhamento político destes fazendeiros faz com que o processo de desapropriação das terras não saia do papel. Por três oportunidades tentaram dar andamento ao processo de desapropriação e, em função de manobras dos interessados, tal processo foi paralisado.

A atuação do Estado é paradoxal, ora fica do lado dos fazendeiros e não resolve a regularização fundiária da área da Reserva, deixando de lado esta situação vivida pelos extrativistas, ora executa o papel de regulador do conflito, fiscaliza o território desta unidade de conservação e acua os fazendeiros com advertências e multas àqueles que não fazem o uso ambientalmente correto das propriedades. Percebe-se, por isso, que cabe ao Estado a resolução do conflito por ele enaltecido, decidindo, finalmente, qual a melhor posição a tomar.

Ao persistir a indecisão vigente por parte do Estado, os entraves da solução estão diariamente se entranhando nos atores sociais envolvidos. Sejam nos fazendeiros, que diariamente investem em seus negócios (pecuária) nessa 
área, sejam nas populações tradicionais que veem o território perdendo seus babaçuais. Por isso, a demora por parte do Estado em resolver o conflito só o fortalece e dificulta sua definitiva solução. Portanto, há necessidade de planejamento e execução da política pública ambiental (efetivação da Resex) e, caso isso não ocorra, há o risco de que a situação, indefinida como se encontra, possa modificar os hábitos e modos de vida dessa população tradicional que vive, principalmente, do extrativismo do babaçu. Ademais, pode ser que, em um futuro próximo, não haja mais babaçuais neste local, em razão da expansão da pecuária nesta área da Reserva.

\section{Referências}

Behr, M. V. (1995). Reservas Extrativistas do Extremo Norte do Estado do Tocantins, da Mata Grande e do Ciriaco. J. R. Murrieta e M. P. Ruenda, (orgs.). Reservas Extrativistas (pp. 105-115). Gland, Suíça, Cambridge e Reino Unido: União Mundial para a Conservação.

Brasil (1992). Decreto $n^{0}$ 535. Cria a Reserva Extrativista do Extremo Norte do Estado do Tocantins. Disponível em http://presrepublica.jusbrasil.com.br/legislacao/113512/decreto-535-92

Brasil (1990). Decreto $n^{o}$ 98.897. Dispõe sobre as Reservas Extrativistas e dá outras providências. Disponível em http://www.senado.gov.br

Bourdieu, P. (1998). O poder simbólico. Rio de Janeiro: Bertrand Brasil.

Castilho, M. W. V. de (2009). Documento Final da Caracterização da Reserva Extrativista do Extremo Norte do Tocantins. Instituto Chico Mendes de Conservação da Biodiversidade, Brasil.

Dias, L. de O. (2005). Mulheres de fibra: as estratégias das quebradeiras de coco no Tocantins como um marco empírico para o desenvolvimento sustentável (Tese de Mestrado Inédita). Mestrado em Ciências do Ambiente. Universidade Federal do Tocantins, Palmas.

Kotscho, R. (1981). O massacre dos posseiros: conflito de terras no Araguaia-Tocantins. São Paulo: Brasiliense.

Martins, J. de S. (1981). Prefácio. Kotscho, R. O massacre dos posseiros: conflito de terras no AraguaiaTocantins. São Paulo: Brasiliense.

Martins, J. de S. (1991). Expropriação e violência: a questão política no campo. (3ª ed.). São Paulo: Hucitec.

Nascimento, D. T e Bursztyn, M. A. A. (2010). Análise de conflitos socioambientais: atividades minerarias em comunidades rurais e Áreas de Proteção Ambiental (APA). Revista Desenvolvimento e Meio Ambiente, 22, 65-82.

Pereira, A. dos R. (2010). Conflitos de terra e violência no sul do Pará (1975-1990). Em X Encontro Nacional de História Oral. Anais... Recife, PE, 26 a 30 de abril de 2010.

Santos, J. V. T dos (2002). Violências, América Latina: a disseminação de formas de violência e os estudos sobre conflitualidades. Sociologias, 8, 16-32.

UFV/ICMBio. (2014). Apoio ao processo de identificação das famílias beneficiárias e diagnóstico socioprodutivo em Unidades de Conservação Federais ( $1^{a}$ ed.). Viçosa-Brasília.

Yohannes, L. (2013). The evolving importance of babassu (Attaleaspeciosa) to the livelihoods of the extractivist communities of Extremo Norte Extractive Reserve, Brazil (Unpublished Master's Thesis). University of Maryland, Baltimore, EUA. 